\title{
Discussion on Selection of Accounting Methods for University-affiliated Hospitals
}

\author{
Lu-Lu MA \\ Shandong Normal University, Jinan, China \\ malulu9311@163.com
}

Keywords: University-affiliated hospital, Cash basis of accounting, Accrual basis of accounting.

\begin{abstract}
Most of affiliated hospitals to colleges and universities are subordinate to the financial departments. Cash basis of accounting is used in these hospitals. But with the introduction of the new Financial Regulations for Institutions of Higher Learning, more requirements are imposed on cost accounting and performance appraisal, which makes the strengths of accrual basis of accounting more visible. In this paper, the author conducts a comparative study and draws a conclusion that adding accounts receivable and payable and accrual basis of accounting to the existing cash basis of accounting is conducive to the authenticity of financial information.
\end{abstract}

\section{Introduction}

On December 19, 2012, the Ministry of Finance and the Ministry of Education issued the new "Financial Regulations for Institutions of Higher Learning". These regulations provide new rules for financial management of universities, including standardization of cost accounting. These regulations demand that the universities should refine their cost accounting, implement performance appraisal, and improve efficiency to meet their needs for development. At present cash basis of accounting is often used in public institutions for their financial management, as the cash index is suitable for the current budget management. However, the new regulations are posing higher requirements on financial cost accounting and performance appraisal of universities. In this case, the strengths of accrual basis of accounting are more often talked about, because this methodology could reflect a full spectrum of information about assets, liabilities, income and expenses to meet the need for performance appraisal. Affiliated hospitals, as part of the university's financial accounting, are financially managed by the university's financial department. However, the particularity of these hospitals creates a more pressing need for cost accounting, and accrual basis of accounting turns out a more suitable choice.

\section{Status of Financial Accounting in University-affiliated Hospitals}

\section{Diversified Fund Sources of University-affiliated Hospitals}

A university-affiliated hospital is a secondary unit subordinate to a university, and its source of funds is much more complex compared with other departments or administrative organs. Taking a normal university in Shandong as an example, its affiliated hospital has four fund sources. The first is the university's budget, covering lump sum funds for official business such as travel expenses, conference fees, purchase fees of office supplies, personnel expenses such as base pay and merit pay of hospital staff, as well as medical expenses of retirees, including outpatient costs and hospitalization fees of retired cadres. The second is medical insurance appropriation by the provincial medical insurance authority. As the university's community hospital, the affiliated hospital will submit statements on actual medical expenses to the provincial medical insurance authority on a regular basis and receive appropriations for reimbursement of outpatient expenses and hospitalization expenses of the university's in-service and retired employees, as per the Instructions for Medical Service Settlement of Personnel Covered by the Medical Insurance in Institutions Directly under the Province issued by the Provincial Social Security Administration. The third is social security appropriation for the students. When the students report to the university, they will be covered by the medical insurance for urban residents, and all the outpatient and 
hospitalization expenses which occur during their stay at the university will be reviewed by the municipal medical insurance authority and repaid by the appropriation. The fourth is subsidy received for providing community services as an essential public health services provider, inclu ding financial arrangements and social donations for free basic public health services for rural and urban residents provided by primary health care institutions.

\section{Backward Cost Accounting of University-affiliated Hospitals.}

The diversity of fund sources makes cost accounting highly complex, while the current cost accounting practices in university-affiliated hospitals lags far behind the time. On the one hand, a university-affiliated hospital is a secondary unit of the university, with its finance being managed as part of the university's by means of cash basis of accounting, that is, making budget at the beginning of each year and settlement at the end. Where the appropriation for free medical service is insufficient and the deficit is huge, the university will provide supplemental appropriations. But on the other hand, the university-affiliated hospital is also part of the social medical service domain, and could make money from outpatient and physical checkup services, which, however, result in costs of medicine and labor. The office buildings and major medical equipment have to be purchased by requesting budget from the university, usually without sufficient feasibility study. The fact behind such unwarranted purchase and renovation of fixed assets is the focus on investment and indifference towards service, resulting in huge waste of money. But in cash basis of accounting, accrual of depreciation is not considered; as such the medical cost could not faithfully reflect the status of university-affiliated hospitals. In addition, the use of provincial and municipal medical insurance and other social security insurance funds results in delayed settlement of the hospital's medical income. With the current cash basis of accounting, only the cash received in the current period is recognized as income and the cash disbursed in the current period recognized as expenditure. The cost of the current period is untrue, and the income and cash could not match, which is not good for performance appraisal.

\section{Selection of Accounting Method for University-affiliated Hospital}

With the continuous deepening of reform of medical insurance system, more people are covered by the system, including retirees and in-service employees of business establishments, and staff of public institutions since 2012. The university's employees and students will result in much more medical expenses than those who have access to free medical services. Health insurance funds are becoming the main source of income for university-affiliated hospitals How to improve the accounting of medical costs and ensure legal and rule-compliant use of medical insurance funds is a problem faced by university-affiliated hospitals.

The traditional cash basis of accounting is suitable for the budgeting of university-affiliated hospitals, but if it is used as a basis for performance appraisal, its cost accounting method is too simple to delineate the operating and non-operating business, so the costs cannot be accurately accounted for. The strengths of accrual basis of accounting lie in that the income-expense ratio can be determined, so it could better reflect the real business results. For example, the outpatient revenue of a university in January is 500,000 yuan, of which 400,000 is from medical insurance and 100,000 yuan from bank deposits, and the medical expenses are 400,000 yuan. In February the outpatient revenue is 600,000 yuan, of which 450,000 yuan is from medical insurance and 150,000 yuan from bank deposits, and the medical expenses are 480,000 yuan. To obtain appropriation from the medical insurance authority, the hospital has to submit a statement. Assuming that an appropriation of 400, 000 yuan is acquired on February 3 and 450,000 yuan on February 27, according to the cash basis of accounting, the medical income recognized in January is 100000 yuan and the medical expenses recognized are 400,000 yuan, recording a loss of 300,000 yuan for the month. The recognized medical income in February is 850,000 yuan and the medical expenses are 480,000 yuan, recording a surplus of 370,000 yuan for the month. While according to the accrual basis of accounting, the recognized medical income and expenses in January are respectively 500,000 yuan and 400,000 yuan, recording a surplus of 100,000 yuan. In February, the 
recognized amounts are respectively 600,000 yuan and 480,000 yuan, the monthly surplus being 120,000 yuan. This example shows that the fluctuated operating results recognized using the cash basis of accounting reflect unstable operation of the hospital, possibly involving management defects or major public health events. In fact, the operating results determined using the accrual basis of accounting more accurately reflect the real operation status, which is steadily rising. Thus, under the existing financial accounting system, setting up a "medical expenses receivable- medical insurance fund receivable" account is indeed necessary. Combining cash basis of accounting and accrual basis of accounting could on the one hand meet the hospital's requirements on accuracy of revenue accounting and cost accounting regarding medical insurance fund, and on the other hand ensure a smooth interface with the university's financial budget management. Introducing the accrual basis of accounting can make the accounting of medical insurance fund more convenient. In addition, accrual basis of accounting is also favorable for dealing with medical insurance. For example, a student receives intravenous injection at the hospital. The medical fee is 300 yuan, of which 200 yuan is paid by the student and 100 yuan by the medical insurance. The medicine charge is 200 yuan. For billing, a debit of 200 yuan is kept in cash balance, a debit of medical service charge receivable is kept and a credit of 300 yuan is kept in medical service income. The medical insurance amount receivable is 100 yuan, a credit of 300 yuan is kept for medical service charge, and a credit of 200 yuan is kept for medicine inventory. Obviously the medical service income of 300 yuan matches with the medical service charge of 200 yuan. But it can be seen from the two accounting entries that the hospital makes a profit of 100 yuan. If the data needs to be adjusted due to a calculation error during settlement between the hospital and medical insurance authority, the medical service income will be adjusted based on the amount of error. In the example, the medical insurance authority actually pays 190 yuan, then a debit of 10 yuan is kept for medical service income, and a credit is kept for medical service charge, the medical insurance payable being 10 yuan. It is clear that the accrual basis of accounting makes the responsibilities better defined, and is more helpful in performance appraisal in public institutions.

\section{Summary}

With release of the new Financial Regulations for Institutions of Higher Learning and promotion of the medical insurance system, university-affiliated hospitals are facing unprecedented opportunities for development. In the transformation from relying purely on budget appropriations to comprehensive use of medical insurance funds to serve the university's staff and students, a proper accounting method for accurate accounting of medical cost and income is an indispensable administrative measure. Introducing accrual basis of accounting as a supplement to the existing cash basis of accounting could meet the current needs of university-affiliated hospitals and lay a foundation for their community services in the future.

\section{References}

[1] Yang Yijun, A Brief Interpretation of Reform in Accounting of Medical Insurance Fund, Introduction to Economic Research. 20 (2013) 214-215.

[2] Di Chengyu, Discussion on Financial Accounting and Management under the New Hospital Accounting System, Chinese Township Enterprises Accounting, 10 (2013) 108-109.

[3] Miao Xin, On Financial Management of University-affiliated Hospitals in the Background of Nation-wide Medical Insurance Coverage, Scientific Management, 7 (2013 )25-27.

[4] Liu Qing, Discussion on Financial Management of University-affiliated Hospital, Introduction to Economic Research, 24 (2013) 201-202.

[5] Xie Dandan, Some Thoughts about Cost Accounting under the New Hospital Accounting System, China Management Information Technology, 18 (2011) 21-22. 